\title{
Examining Some of Students' Views on the Nature of Science (NOS) in Traditional Lecture Format Teaching Environment
}

\author{
Issa I. Salame ${ }^{a, *}$, Shirley Dong ${ }^{b}$ \\ a The Department of Chemistry and Biochemistry, The City College of New York of the City University of \\ New York, United States \\ ${ }^{b}$ Department of Education, Hunter College, of the City University of New York, United States \\ $a^{\star}$ Corresponding author: isalame@ccny.cuny.edu
}

Received: February 24, 2021; Accepted: October 05, 2021; Published: October 15, 2021

\begin{abstract}
The preparation of a scientifically literate society is the main goal of science education throughout the world and this has resulted in the emphasis of nature of science in the curriculum. The purpose of this research project is to examine the aforementioned students' views on NOS tenets, its relationship to their academic achievements and background, and how it changes through their study of science. The study took place at the City College of New York, an urban, commuter, public college, and minority serving institute. The research data was collected through the administration of a survey that contained three of the NOS questions and academic and background information about the students. The data suggest that students possess inadequate understanding of the nature of science when they begin their academic fields of science study. This inadequate understanding is resistant to change in traditional science teaching settings. The data provide evidence that the inadequate understanding of nature of science does not change as the result of exposure to science courses, the field of science studied, and the students' academic achievement as measured by grade point average. Our data show that traditional instruction in college science courses does not address nature of science and does not cause a conceptual change in the students' understanding of NOS. The lack of correlation between students' understanding of nature of science and credits completed or grade point average could be attributed to students relying on rote-learning and algorithmic problem-solving to achieve high grades and succeed in science, which hinders their meaningful learning of science and the development of conceptual understanding. Thus, science teaching and instruction should address naïve conception on the NOS and changes the instruction methods to consider NOS naïve conceptions and learning challenges. Science teaching and learning curriculum and instruction should immerse students in science learning activities that nurtures their understanding of the nature of science through participating in novel science research and inquiry-based learning activities.
\end{abstract}

Keywords: Nature of Science, conceptual understanding, rote-learning

\section{INTRODUCTION}

For over a century, many researchers, science educators, and policy makers have made enormous effort to emphasize the need to develop students' views of nature of science (NOS) [1-2]. This advocacy to improve students' understanding of NOS continues to be an important aspect in science education and science education research, as well as major science education reforms [1, 3]. Now many nations, including Australia, Canada, South Africa, the United States of America, and the United Kingdom, have adapted the teaching of NOS as part of the school curriculum [4].

The precise definition of NOS has been a contentious topic amongst sociologist, philosophers, as well as science educators and researchers. The issue arose from disagreements regarding theuniversal 
definition of NOS (i.e. the NOS), what specific areas does NOS include, is there various degrees to which NOS applies to specific scientific fields as compared to scientific discipline as a whole [5-6]. Nonetheless, the current general consensus in the science education community is that NOS is the epistemology of science, science as a way of knowing, or the values and beliefs inherent to the development of scientific knowledge [7]. The general censuses on contemporary aspects of NOS explain that scientific knowledge is tentative which is based on empirical evidence and law and theory. Scientific laws and theories are, for instance, different types of knowledge. on the other hand, science is a human enterprise and collaborative, creative and subjective (theory-laden), packing up in culture and society, and usingmany research methods [8].

The one of main goal of science education is preparing a scientifically literate society, which include the development of the learners' scientific knowledge, processes, nature of science, and use of scientific knowledge [9]. Subsequently, being scientifically literate involves understanding the different components of the NOS [10]. Moreover, knowledge of NOS is essential to increase scientific literacy [10]. Adequate NOS understanding probably can alsoclarify misconceptions.

The several barriers in the way of conceptual understanding of science can be lowered with sufficient awareness of its epistemology. Therefore, all serve could increase an individual's appreciation for science. Moreover, it can help individuals make informed decisions on science-related personal and societal dilemmas [11]. Controversial issues that relevant to recent and many future generations that including climate change and genome editing. It will take scientifically informed individuals to help determine the best solution(s) to the problems that society and the environment currently faces and will face.

Scientists depend on empirical evidence to support claims about natural phenomena. The evidence from observations and experiments must be reproducible in order to garner support for the discovery and/or idea. Reproducibility also helps to limit errors and biases. An important note on biases in science is that they are inevitable since science is a human endeavor and embedded within the sociocultural context. However, scientiststry to limit the biases by ensuring that results can be reproduced, as well as repeated and replicated, and use various self-check systems, such as peer review. Overall, science is different from other disciplines as it relies on empirical evidence and reproducibility of evidence to support ideas [12].

Laws and theories are both important in science, but they serve different functions and thus, one cannot become the other nor is there a hierarchical relationship $[1,12]$. Laws describe or predict natural phenomena. An example is the ideal gas law, which relates pressure, temperature, and volume in ideal conditions, and can be used to predicate the behavior of the ideal gases. Nevertheless, theories explain natural phenomena. An example is the kinetic molecular theory of gases, which explains the ideal gas law. Scientific knowledge, such as law and theory, is not absolute. The atomic theory, for example, has changed and evolved overtime with new evidence and perspectives on the theory, and advances in technology. Thus, scientific knowledge is not "proven" or "true" since it is subject to change to account for new developments that the scientific community has a consensus or developing consensus on $[1,12]$.

There are numerous studies on elementary to high school students, pre-service and in-service teachers, researchers, and university professors [13-14]. Many have also provided instructional methods in an attempt to improve NOS understanding scientific literacy [15-16]. However, , the research studies show that both high school students and teachers have insufficient understanding and even misconceptions regarding NOS continuously. This inevitably have detrimental impacts on students as they enter college and how they view science.

Research about university students' views on NOS is much more limited than the studies on nonundergraduate students' views [11]. However, it is known NOS aspects are not explicitly taught in nonteacher education programs, at least at the time of this project in the United States. Instead the focus, at the collegiate level, is placed on content knowledge and research skills. In addition, various factors such as insufficient NOS knowledge in in-service teachers-misconceptions about science-is causedby mainstream culture and oversimplifying of scientific knowledge. Consequently, it has led to gaps in students' NOS knowledge. Below are some relevant studies available at the time of writing this paper.

Karakas (2008) examined undergraduate students', mostly female and between 18 to 20 years old, ideas about NOS [17]. The participants were enrolled in a biology course at a university in northeastern United States. The instrument was a questionnaire containing a total of nine questions, five Yes/No questions and four open-ended questions. The study concluded that there was no statistical difference 
amount the three groups, science majors, non-science majors, and undecided, and on average held naïve to developing views of NOS.

Parker et al (2008) used Views of Nature of Science Questionnaire, Form C (VNOS-C), the openended instrument to study upper-level atmospheric science students' NOS views [18]. The results from the study was that the students held some non-informed ideas about science, such as the purpose of science is to "prove" ideas and that there is and there exists a hierarchical relationship between theory and law.

Miller and his co-workers (2010) examined undergraduate students in lower- and upper-level science courses. The instrument used contained Likert-scale items and open-ended prompts [19]. The results showed that there was no statistical difference between students in the lower- and upper-level courses. On average, students held developing views on the change of scientific theories but had naïve understanding of scientific theories vs. scientific laws. Overall at both levels, students on average held naïve to moderately inform views.

Samara (2015) used an instrument containing 23 items that covered five domains of NOS to examine the undergraduate students' views [20]. These students were randomly selected. They were majoring in science or science education at a university in Jordan. The results showed that the average student held developing views on NOS and that there was no statistical difference in the data between students majoring in science and those majoring in science education.

\section{METHODS \\ Method of Qualitative Analysis}

This research study focused on three parts from the nature of science. First, the empirical nature of science which relevant with the fact of scientific knowledge is accumulated through the data collection with a scientists' support through the claimed data. Second is the tentative nature of scientific knowledge where scientific knowledge may be replaced with the new one in light of the new data collected or the reinterpretation of the existent data. Third is theories/laws where theories and laws have different nature. Theories do not turn into laws with adequate evidence. Theories have an explanatory nature whereas laws have a descriptive nature that describes what happens under certain circumstances [21].

\section{Guiding Research Questions.}

Our research was structured to address the following specific questions:

1. What are the aforementioned students' views on the three selected NOS tenets?

2. Do the aforementioned students' views on the three selected NOS tenets relate to their academic (i.e. college science courses completed, GPA, and major) and personal background (i.e. gender)?

3. In what ways, if any, do student NOS views change through their study of science?

The purpose of this investigation was to understand undergraduate students' views on three specific aspects of Nature of Science. These tenets were that scientific knowledge that based on empirical evidence, theories and laws, and (3) tentative. The particular undergraduate student group of interest were students attending a public university in New York City.

The participants in this study were undergraduate students at a college part of the largest urban university system in the United States, City University of New York (CUNY). New York City's public university system, founded in 1847, is institution that has "propelled almost six times as many low-income students into the middle class and beyond as all eight Ivy League campuses, plus Duke, M.I.T. Stanford and Chicago, combined".

Founded in 1847, The City College of New York (CCNY) is one of the original public higher-education institutions in New York City. The participants were students at CCNY in the Fall 2019 semester. According to the college's undergraduate student demographic information for Fall 2019, 92\% of its undergraduate population were residents in New York State (i.e. 81\% lived in New York City and 11\% lived in New York State excluding NYC) and 8\% lived in other places. The ethnic makeup at the undergraduate level consisted mostly of Asian, Black, Hispanic, and White students. The ages range from under 19 to over 45 with a majority of the students between 20 to 22 years old. Most of the undergraduate students majored in engineering, humanities, sciences, or were undeclared. The biological sex population was $52 \%$ female and $48 \%$ male. 
There was a total of 236 participants from the aforementioned public university. At the time of this study, the age of the participants ranged from 17 to 38, with the average age of 20 years old $(n=218)$. Furthermore, the participants were $21 \%$ freshman $(n=48), 33 \%$ sophomore $(n=76), 21 \%$ junior $(n=49)$, $20 \%$ senior $(n=46)$, and 5\% post-bac $(n=11)$. The participants completed between zero to over 15 college-level science class. It is worth mentioning that those who completed zero college courses were enrolled in at least one science class at the time of the data collection around the middle to end of the Fall 2019 semester since the surveys were only distributed in science courses, and the same logic applies to those who completed one or more science courses.

TABLE 1. Distribution of the number of science courses the participants had completed by the time of the questionnaire.

\begin{tabular}{cc}
\hline $\begin{array}{c}\text { Number of college science } \\
\text { courses completed }\end{array}$ & Percentage \\
\hline Between 0 to 2 & $50 \%$ \\
Between 3 to 5 & $25 \%$ \\
Between 6 to 8 & $6 \%$ \\
Between 9 to 11 & $5 \%$ \\
Between 12 to 14 & $6 \%$ \\
15 and over & $8 \%$ \\
\hline
\end{tabular}

Table 2 summarizes the participants' majors, which were categorized into six main groups: life science, physical science, engineering, social sciences, dual major, and undeclared categories. Many of the participants declared a major in the life sciences, engineering, or physical sciences.

TABLE 2. Distribution of the participants' major at the time of the questionnaire.

\begin{tabular}{lc}
\hline \multicolumn{1}{c}{ Major } & Percentage \\
\hline Life sciences & $34 \%$ \\
(i.e. biology, biomedical sciences, & \\
biotechnology) & \\
$\begin{array}{l}\text { Physical sciences } \\
\text { (i.e. chemistry, earth sciences, } \\
\text { physics) }\end{array}$ & $14 \%$ \\
$\begin{array}{l}\text { Engineering } \\
\text { (i.e. biomedical, civil, computer, }\end{array}$ & \\
electrical, environmental, mechanical) & $28 \%$ \\
$\begin{array}{l}\text { Social sciences } \\
\text { (i.e. anthropology, psychology) }\end{array}$ & \\
Dual Major & $10 \%$ \\
Undecided & $2 \%$ \\
\end{tabular}

Table 3 tabulates the grade point average (out of 4.0) of the participants. Most of the undergraduate students had GPAs between 3.50 to 3.74 with the GPAs between 3.0 to 3.24 as the second most abundant range.

TABLE 3. Distribution of the participants' GPA range at the time of the questionnaire.

\begin{tabular}{lc}
\multicolumn{1}{c}{ Grade Point Average } & Percentage \\
\hline Below 3.0 & $9 \%$ \\
Between 3.0 to 3.24 & $28 \%$ \\
Between 3.25 to 3.49 & $12 \%$ \\
Between 3.50 to 3.74 & $29 \%$ \\
Between 3.75 to 4.00 & $22 \%$ \\
\hline
\end{tabular}


The biological sex of the participants reflected those in the entire ungraduated level of CCNY, with the exception that the ratio of female to male is slightly greater in this study.

This was a cross-sectional study of the university students' views. Professors and instructors of science classes were contacted to receive approval to prior to administering the instrument. These classes were first and second semester general chemistry courses, biochemistry, and physical chemistry. Once approval was confirmed, the questionnaire forms were administered the agreed upon date and time for each class. Prior to distributing the surveys to the students in class, the administrating researcher gave a brief overview of the project and informed the participants that the survey was anonymous, does not influence their grade, and completely voluntary. This was all done to follow the college's research guidelines regarding experiments that deal with human subjects.

Since the questionnaires were given to students during class time, there was a time constraint of 15 minutes for the participants to answer the questionnaire. The form used in this study was a modified version of VNOS-C to examine NOS understanding [1]. Four questions from the original VNOS-C were selected to help determine the undergraduate students' views on the aspects and additional questions were added to gather demographic information (i.e. age, college level, gender, GPA, major, and number of completed college level science courses). After the students answered the questionnaire to the best of their ability, the forms were turned in upside-down to protect the participants' anonymity.

A total of 236 questionnaire forms were collected and analyzed for this study. The demographic information was analyzed as well as the students' responses. For each participant, their responses to the four NOS aspect questions were looked at holistically to identify their understanding of the empirical nature, function of laws and theories, tentativeness of scientific knowledge. A grade of 1 (Unclassifiable) was given for a NOS aspect if the response(s) for it was missing or the response(s) was unrelated to the NOS aspect. A grade of 2 (Naïve View) was given for a NOS if the response(s) showed insufficient or very general understanding of the aspect. A grade of 3 (Developing View) was assigned to the NOS being analyzed if the participant's response(s) showed general understanding but lack a deep understanding, such as not fully answering the prompt, showed misconceptions, and/or were contradictory. The highest point value, 4 (Informed View), was assigned to the NOS aspect where the response(s) that showed a comprehensive understanding of the NOS aspect. The specific details for how the point value and classifications were assigned for each NOS aspect based on a rubric. This process was repeated for until all 236 surveys were analyzed. The averages for each aspect was then calculated based on numbers of complete college science courses, major, GPA, and biological sex and the data was then analyzed.

\section{RESULTS AND DISCUSSION}

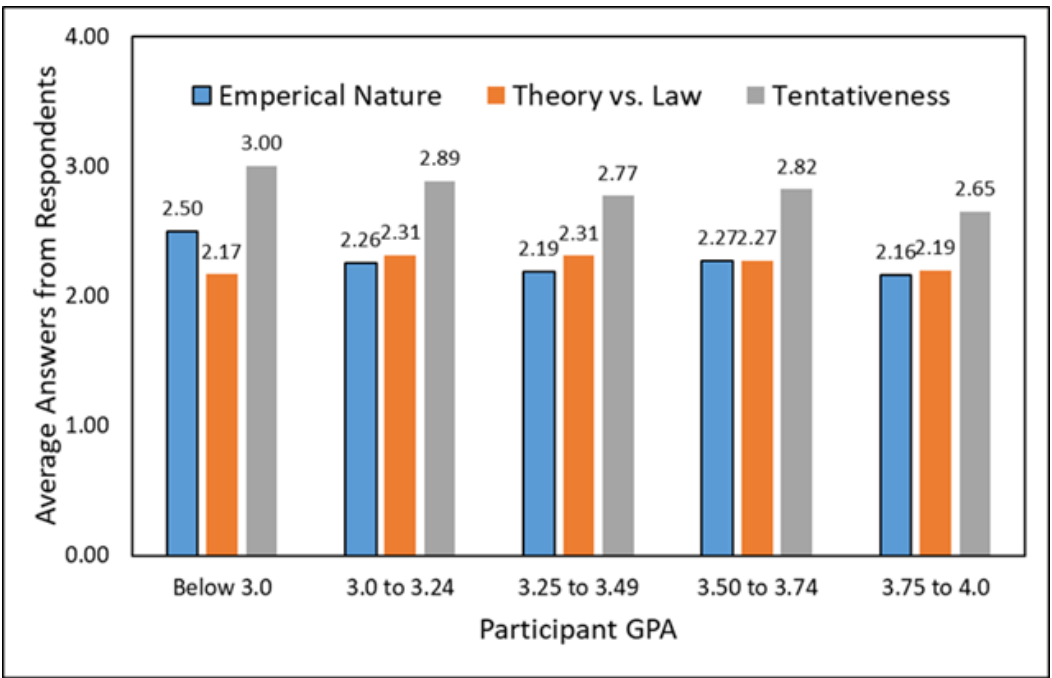

FIGURE 1. Average score on NOS tenets based on participant's GPA. 
Figure 1 data suggest that students have a naïve understanding for the empirical nature of science and theory/law questions. For the tentative nature of science, the students exhibit a transitional understanding which is between naïve and informed. Our data is consistent with research in the field where in one research article, researchers report that majority of their student subjects held naïve views, exhibited little awareness, and possess fragmented and inadequate understanding about the nature of science [22]. Additionally, our data suggest that the students' views on empirical and tentative nature of science and theory/law parts of science did not change with students' grade point average and remained statistically unchanged regardless with students' grade point average. Also, traditional teaching approaches focuses on problem solving and material content without much effort into integrating the nature of science into the science curriculum. There is a significant gap between practice and research when it come to the application of NOS into teaching and learning environments [4].

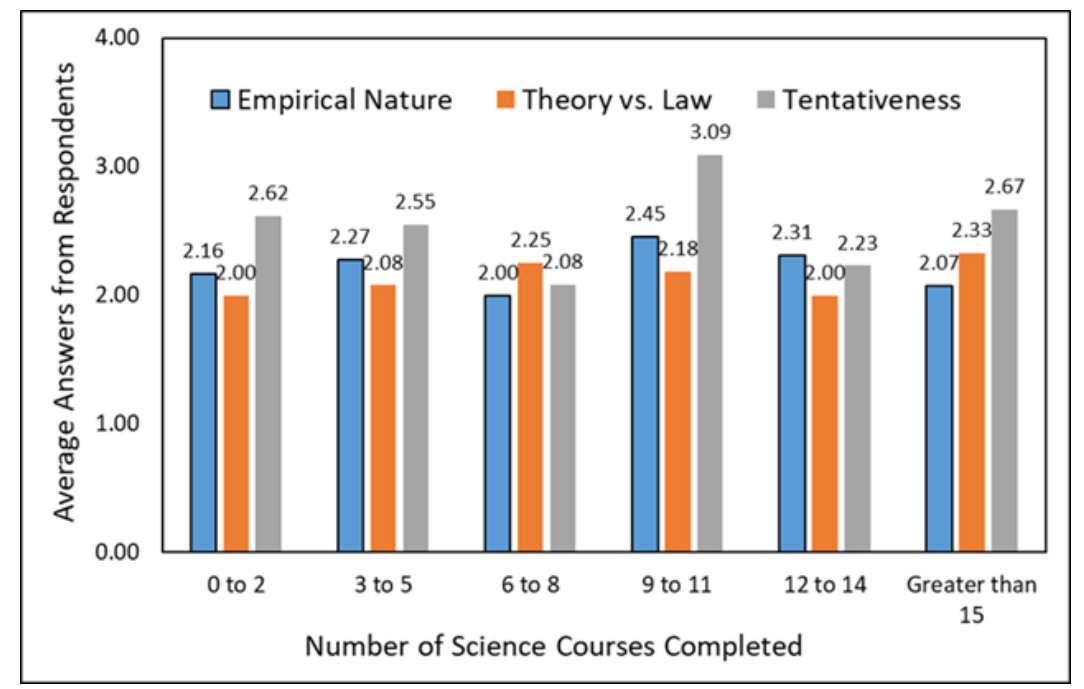

FIGURE 2. Average score on NOS tenets based on number of college science courses completed by participants.

Figure 2 presents the data for students' understanding of the three parts of VNOS and its relationship to the number of science courses completed. The data suggests that the students possess naïve to transitional understanding for the empirical and tentative nature of science and laws and theories. It is noteworthy that we found no correlation for students' understanding of VNOS and number of science courses completed. In one study out of Korea, researchers report that they found no differences in the VNOS in 6th, 8th, and 10th grades [23]. Furthermore, this might have to do with fact that traditional science instructors focus on teaching content, process skills, and problem solving without explicitly addressing nature of science. College instructors assume that science courses nurture the development of scientific literacy and thus emphasize the teaching of science content, problem solving, and process skills instead of NOS [24]. Additionally, it is difficult to cause a conceptual change in students' views on the nature of science with traditional lecture teaching methods. Students' naïve conceptions are resistant to change with traditional instruction which is supported by research stating that naïve conceptions are challenging to change [25]. 


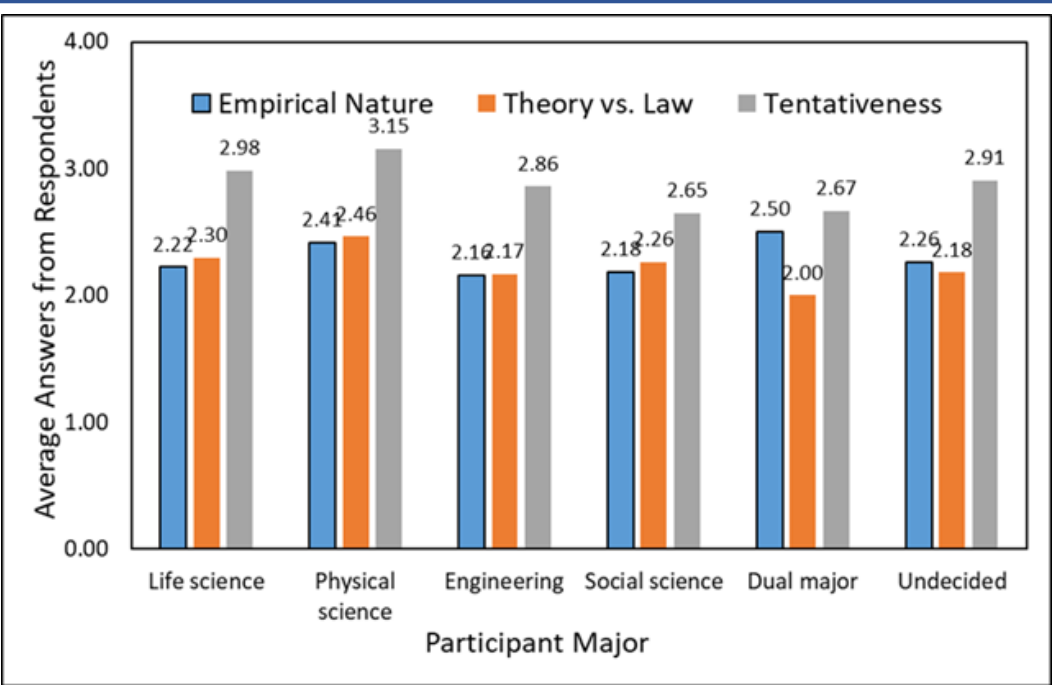

FIGURE 3. Average score on NOS tenets based on participant's major.

Figure 3 describes the students' understanding of empirical, tentativeness, and theory vs. law aspects of nature of science and its relationship to the respective major. Similar to figures 1 and 2, the data shows that students have naïve to transitional understanding of these concepts. Also, like the previous figures, we could not find any correlation between students' understanding of VNOS and their chosen major. This could be attributed to the way students view science as a discrete collection of fact that they can learn by memorization. This is consistent with other findings in the field where students have been found to possess inadequate understanding of VNOS and think that of science as a list of fact that one can memorize [26]. Also, it is challenging to change students' VNOS through traditional instructional methods. Reports from science education research shows that students, as well as, teachers possess an inadequate epistemological understanding of NOS which could be attributed to the complexity of bring about conceptual change to the VNOS [27].

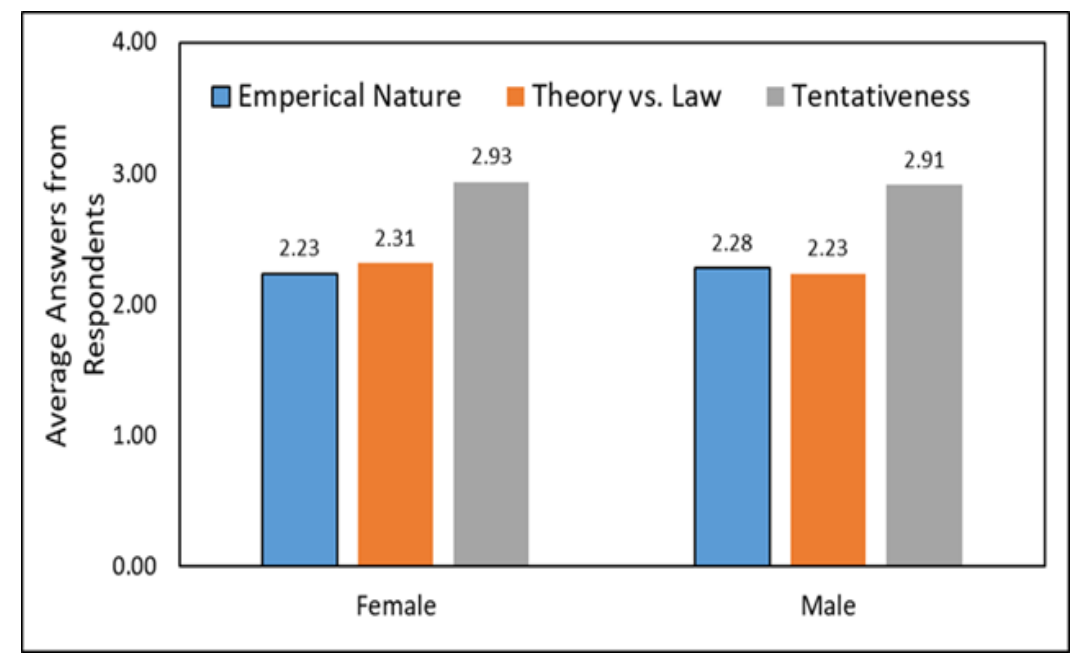

FIGURE 4. Average score on NOS tenets based on participant's gender.

Figure 4 shows the data collected for VNOS understanding and gender. The data show that there is descriptive difference between males and females in our study. Results of recent research indicates that undergraduate students have a transitional understanding of VNOS which is a level between naïve and informed and argue that VNOS should incorporated into undergraduate science curricula [28].

Overall, our data shows that students possess inadequate understanding of the nature of science domains that we studied. This is aligned with other research findings that report that students have 
difficulties in developing understanding of theories/laws, where students believe in the existence of hierarchal relationship between laws and theories, and tentativeness, where students believe that scientific knowledge is made up of absolute facts and that science does not change and evolve, aspects of VNOS [29-30].

Explicit reflective methods to teaching nature of science have been found to positively impact students' understanding of NOS [4]. A recent research paper data suggests that participants possessed naïve and translational VNOS and this was promoted to informed only after explicit-reflective NOS instruction [31]. Furthermore, explicit instruction through argument-driven inquiry on NOS provides a tangible improvement on students' VNOS [32]. Additionally, instructors should provide students with learning opportunities that focus on inquiry-based learning which can impact the understanding of the nature of science [33].

\section{CONCLUSIONS}

The research results show that students possess inadequate understanding of the nature of science when they begin their academic fields of science study. This inadequate understanding is resistant to change in traditional science teaching settings. Data provide evidence that the inadequate understanding of nature of science. It does not change by learning processes. The result, for instance, is the high exposure of science courses through taking multiple science courses, the field of science studies through the major chosen and studies, and though the students' grade point average and academic performance in science courses. Additionally, the data shows that science students' understanding of nature of science does not improve during their science studies. They hold onto their simplistic and hierarchal views of science. The lack of correlation between understanding of nature of science and achievement as measured by grade point average or number of science courses completed provide a valuable information about how students rely on algorithmic problem-solving approaches and rote-learning to achieve higher grades in science, which cannot be used to gauge and measure students' success and achievement.

Based on the results of this study, it could be concluded that traditional instruction in college science courses does not address nature of science and does not cause a conceptual change in the students' understanding. Those science teaching and instruction should address naïve conception on the VNOS and changes the instruction methods to consider VNOS naïve conceptions and learning challenges. NOS should be explicitly integrated into science curricula courses and taught throughout K-16 levels. Furthermore, science students should participate in learning activities that nurtures their views of NOS through involvement in scientific research and investigations, NOS discussion, and inquiry-based science learning activities. By improving students' learning of science in the classroom, instructors can promote students' abilities to make connection and understandings of the views of nature of science. Learning science should not be predicated upon memorization of disconnected fact and equations or algorithmic problem-solving by should allow students to build an adequate understanding of the nature of science and fundamental elements of science.

\section{REFERENCES}

1. N. G. Lederman, F. Abd-El-Khalick, R. L. Bell, and R. S. Schwartz, J. Res. Sci. Teach. 39, 497-521 (2002).

2. F. Abd-El-Khalick, "Over and over again: College students' views of nature of science", In L. B. Flick and N. G. Lederman (Eds.) Dordrecht, Netherlands (2006).

3. R. S. Schwartz, N. G. Lederman, and B. A., Crawford, Sci. Teach. Edu. 88, 610-645 (2004).

4. N. G. Lederman, "Nature of Science: Past, Present, and Future." In S. K. Abel \& N. G. Lederman (Eds.). Erlbaum, Mahwah, NJ (2007).

5. F. Deng, D. Chen, C. Tsai, and C. S. Chai, Sci. Educ. 95, 961-999 (2011).

6. R. S. Schwartz, and N. G. Lederman, Int. J. Sci. Educ. 30, 727-771 (2008).

7. N. G. Lederman, J. Res. Sci. Teach. 29, 331-359 (1992).

8. F. Abd-El-Khalick, R. L. Bell, and N. G. Lederman, Sci. Educ. 82, 417-436 (1998).

9. F. Abd-El-Khalick, M. Waters, and A-P. Le, J. Res. Sci. Teach. 45, 835-855 (2008).

10. J. Holbrook, and M. Rannikmae, Int. J. Environ. Sci. Educ. 4, 275-288 (2009).

11. B. Ibrahim, A. Buffler, A., and F. Lubben, J. Res. Sci. Teach. 46, 248-264 (2009). 
12. S. Y. Yoon, J. K. Suh, and S. Park, Int. J. Sci. Educ. 36, 2666-2693 (2014).

13. K. L. Cook, and G. A. Buck, G. A. Electro. J. Sci. Educ. 17, 1-24 (2013).

14. W. Sumranwanich, and C. Yuenyong, C. Procedia Soc. Behav. Sci. 116, 2443-2452 (2013).

15. E. E. Kartal, W. W. Cobern, N. Dogan, S. Irez, G. Cakmakci, and Y. Yalaki, Int. J. STEM Educ. 5, 3040 (2018).

16. R. S. Schwartz and G. Mesci, Res. Sci. Educ. 47, 329-351 (2017).

17. M. Karakas, M. (2008). Bulg. J. Sci. Educ. Policy, 2, 233-249 (2008).

18. L. C. Parker G. H. Krockover S. Lasher-Trapp and D. C. Eichinger, Bull. Am. Meteorol. Soc. 89, 1681-1688 (2008).

19. M. C. Miller L. M. Montplaisir E. G. Offerdahl F. C. Cheng and G. L. Ketterling, CBE-Life Sci. Educ. 9, 45-54 (2010).

20. N. Samara, Eur. Sci. J. 11, 290-302 (2015).

21. S. Aydin, and S. Tortumlu, S. Chem. Educ. Res. Prac. 16, 786-796 (2015).

22. U. Sangsa-Arda, K. Thathongb, and S. Chapoo, Procedia Soc. Behav. Sci. 116, 382-388 (2014).

23. S. Kang, L. C. Scharmann, and T. Noh, Sci. Educ. 89, 314-334 (2005).

24. M. Karakas, J. Sci. Educ. Tech. 18(2), 101-119 (2009).

25. G. J. Posner, K. A. Strike, P. W. Hewson, and W. A. Gertzog, Sci. Educ. 66, 211-227 (1982).

26. V. Akerson, J. A. Morrison, and A. R. McDuffie, J. Res. Sci. Teach. 43(2), 914-213 (2006).

27. F. Abd-El-Khalick, Nature of science in science education: Toward a coherent framework or synergistic research and development, Second international handbook of science education, Springer (2012).

28. H. Y. Agustian, Electro. J. Res. Sci. Math. Educ. 24(2), 56-85 (2020).

29. R. Khishfe, and N. Lederman, J. Res. Sci. Teach. 43(4), 395-418 (2006).

30. V. L. Akerson, and L. A. Donnelly, Int. J. Sci. Educ. 32(1), 97-124 (2010)

31. B. Demirdogen, and E. Uzuntiryani-Kondakçı, Chem. Educ. Res. Prac. 17, 818-841 (2016).

32. G. Eymur, Chem. Educ. Res. Prac. 20, 17-29 (2019).

33. V. L. Akerson, and D. L. Hanuscin, J. Res. Sci. Teach. 44, 653-680 (2007). 